\title{
A INFLUÊNCIA DA SOCIALIZAÇÃO SOBRE O PERCURSO DOCENTE DOS PROFESSORES DE EDUCAÇÃO FÍSICA NO INÍCIO DA CARREIRA
}

\author{
Victor Julierme Santos da Conceição \\ Universidade do Extremo Sul Catarinense , Criciúma, Santa Catarina , Brasil \\ Jéssica Serafim Frasson \\ Universidade do Extremo Sul Catarinense , Criciúma, Santa Catarina , Brasil \\ Eduardo Batista von Borowski \\ Universidade do Extremo Sul Catarinense , Criciúma, Santa Catarina , Brasil
}

\begin{abstract}
Resumo
Compreender a influência da socialização na fase de iniciação da docência no processo de tornar-se professor de Educação Física foi o objetivo deste estudo. Investigamos a trajetória e a prática educativa de cinco professores de Educação Física na fase de início da docência. Compreendemos que eles dependem integralmente do processo de socialização, atribuindo aissoo papel fundamental para a fase de entrada na carreira docente, em que os professores iniciantes encontram muitas dúvidas e angústias inerentes à inserção no ambiente escolar. Portanto, a compreensão desses sentimentos atrelados a essa fase pode amenizar esse processo com o acolhimento por parte da própria instituição e de seu corpo docente.
\end{abstract}

Palavras chave: Início da Docência. Formação Inicial. Socialização Docente.

\section{Introdução}

Marcelo $(2010$, p.30) afirma que a socialização "[...] é o processo mediante o qual um indivíduo adquire o conhecimento e as destrezas sociais necessários para assumir um papel na organização". Com a contribuição deste autor, buscamos compreender a influência da socialização docente no processo de tornar-se professor de Educação Física. Desta forma, nos dedicamos a compreender as interações sociais estabelecidas a partir do momento em que os professores se inserem no contexto da escola e passam a vivenciar a realidade cotidiana da cultura escolar.

Recorremos a Huberman (1995) para entender e apresentar que o professor iniciante se caracteriza pelos três primeiros anos de trabalho docente, momento em que algumas dúvidas e incertezas surgem, por exemplo: 
Como ensinar? O que ensinar? O que os alunos precisam aprender? Qual a melhor didática?

Este processo de incertezas é acompanhado pelo que o autor descreve como o "choque com o real", que se refere, sobretudo, à diferença entre o real e o ideal, ou seja, entre aquilo que é idealizado pelos estudantes durante o curso de formação inicial e aquilo que efetivamente ocorre no dia a dia da escola.

Considerando que o processo de construção do ser professor se dá desde o período de estudante nas escolas de educação básica, é possível dizer que o futuro professor é alimentado por experiências adquiridas muito antes da sua formação e até mesmo da escolha da sua profissão. Mizukami (1996) afirma que tornar-se professor é um caminho que tem início nas primeiras vivências escolares. É através destas experiências como estudantes que os professores se constroem, se familiarizam com a cultura escolar e entram em contato com os"nativos" da escola (caracterizados como alunos, direção, funcionários e colegas docentes).

Esta socialização entre os sujeitos que constroem mecanismos de rotina nesta realidade de vida cotidiana (BERGER; LUCKMANN, 2012) se dá em todo o contexto escolar e, de fato, torna-se de grande importância quando acontece permeada pela organização escolar. Innone (2006) observa que a "organização escolar" pode ser definida como "um conjunto de indivíduos que utilizam um conjunto de meios para realizar tarefas coordenadas em função de objetivos comuns". Outra definição é pensar a organização como "um coletivo humano coordenado, orientado por uma finalidade, controlado e atravessado pelas questões do poder" (INNONE, 2006). Sabendo da dificuldade de conceituação, da singularidade do universo escolar e da complexidade de fatores que interferem na compreensão de organização, buscamos a definição de Hall (1984, pg. 23).

De acordo com o autor, uma organização é uma coletividade com uma fronteira relativamente inidentificável, uma ordem normativa, escalas de autoridade, sistemas de comunicações e sistemas de coordenação de afiliação; essa coletividade existe numa base relativamente contínua num ambiente que se compromete em atividades que estão relacionadas, usualmente, com um conjunto de objetivos.

Dado o exposto, podemos entender que o processo de socialização influencia na construção da identidade docente, pois é nesse movimento de aproximações com os sujeitos que se compõe a vida cotidiana e que começam as trocas de experiências, os acordos no processo de conhecimento dos alunos e também a compreensão sobre a organização escolar (MEDEIROS; CONCEIÇÃO; BOROWSKI, 2012). Além disso, a socialização durante a formação inicial permite ao docente, enquanto estudante, compreender que existem distintas realidades escolares, e ir construindo ao longo do processo

Pensar a Prática, Goiânia, v. 17, n. 2, p. 472-484, jan./mar. 2014 
de formação, a capacidade de reflexão sobre a sua prática educativa no contexto escolar.

Garcia (2010) observa que os professores iniciantes precisam de ideias e habilidades críticas, bem como a disposição para refletir, avaliar e aprender sobre o ensino, para, assim, poderem sempre melhorar como docentes. A organização escolar também tem uma grande função na socialização do professor, pois é a responsável pelo acolhimento do iniciante e, ainda, por dar o apoio necessário para que ele possa se sentir seguro dentro da organização. Contudo, não é raro observar os professores iniciantes assumindo as turmas com maior dificuldade de trato pedagógico, com materiais mais precários, em espaços físicos e horários menos procurados. As melhores condições de trabalho, geralmente, são do professor que está há mais tempo na escola e ele socializa esse espaço/material se quiser, criando assim uma relação de poder entre os mais experientes e os iniciantes.

Em sua dissertação de mestrado, Perin (2009) mostra que na organização escolar todos os envolvidos no processo educativo devem participar de discussões pedagógicas, pois os trabalhos são realizados em diferentes espaços da instituição escolar e não somente nas salas propriamente ditas. Portanto, percebemos que a organização escolar está presente no cotidiano dos professores, e que o iniciante deve estar inserido no contexto para, assim, buscar um melhor entendimento deste espaço.

A organização tem como função abrir espaços e buscar cada vez mais, meios de socialização com os docentes que estão em início de carreira. É nesta perspectiva que este estudo debruça suas intenções em investigar a influência da socialização docente no processo de tornar-se professor de Educação Física na fase de iniciação da docência.

\section{Decisões Metodológicas}

A ação de assumir um determinado enfoque metodológico manifesta a intencionalidade e os pressupostos teóricos do pesquisador. Deste modo, tratar de decisões metodológicas é buscar refletir sobre as metodologias adequadas ou inadequadas para responder a um determinado problema e/ou fenômeno (ALVEZ-MAZZOTTI; GEWANDSZNAJDER, 1998).

Desta forma, é de extrema importância que os caminhos e procedimentos metodológicos tenham ligação direta com aquilo que se quer investigar. Realizando um resgate da proposta deste estudo, justificamos os procedimentos metodológicos a partir do objetivo deste, que é investigar a influência da socialização docente no processo de tornar-se professor de Educação Física na fase de iniciação da docência, procurando compreender as interações sociais estabelecidas a partir do momento em que os professores se

Pensar a Prática, Goiânia, v. 17, n. 2, p. 472-484, jan./mar. 2014 474 
inserem no contexto da escola e passam a vivenciar a realidade cotidiana da cultura escolar.

Trata-se de um estudo descritivo que se debruça na abordagem qualitativa. Fizeram parte como colaboradores de investigação três professoras e dois professores de Educação Física, todos considerados porHuberman (1995) e Garcia (2009) como professores iniciantes (cinco anos de experiência docente). Esses professores participaram de um encontro, uma entrevista semiestruturada, caracterizada por Lakatos; Marconi (2001) como uma forma mais fidedigna para obtenção de informações a respeito de determinado assunto.

As entrevistas foram gravadas, transcritas e passaram por um processo de validação interpretativa quando apresentadas aos colaboradores para análise da fidedignidade das informações. As análises dessas entrevistas serão apresentadas a seguir, organizadas em categorias, a partir do tema proposto. Foram construídas subcategorias que aparecem com maior relevância durante a análise das entrevistas.

Para manutenção dos aspectos éticos da investigação, os colaboradores foram identificados com nomes fictícios, a fim de que, desta forma, fossem preservadas as identidades dos professores. No quadro abaixo, é possível observar o tempo de atuação e os dados de identificação deles. Os colaboradores foram selecionados a partir da participação espontânea, levando em consideração a iniciativa em buscar participação direta na investigação. Esse tipo de participação influencia positivamente no volume e credibilidade de informações disponibilizadas pelos colaboradores (MOLINA NETO, 2010).

Quadro 1: Características e tempo de atuação dos colaboradores da pesquisa.

\begin{tabular}{cccc}
\hline PROFESSOR & SEXO & IDADE & $\begin{array}{c}\text { TEMPO DE } \\
\text { ATUAÇÃ O }\end{array}$ \\
\hline Carmen & F & 24 & 3 \\
\hline Francisco & M & 25 & 4 \\
\hline Luzia & F & 24 & 3 \\
\hline Ana & F & 26 & 3 \\
\hline João & M & 23 & 2 \\
\hline
\end{tabular}

O que se destacou nas entrevistas foi que o processo de socialização está presente de maneira significativa na fase de início da carreira e pode contribuir ou prejudicar a inserção do professor na escola. Destacamos ainda que esse processo, que acontece todos os dias no ambiente escolar, acarreta mudanças significativas na prática pedagógica, levando a uma aproximacão Pensar a Prática, Goiânia, v. 17, n. 2, p. 472-484, jan./mar. 2014 
ou a um distanciamento dos professores e, em consequência, da escola com o seu projeto pedagógico.

\section{O processo de socialização docente de professores de Educação Física}

Na busca por descrever o processo de socialização docente encontramos nas falas dos professores de Educação Física entrevistados, "facilidades/dificuldades em ingressar/integrar o corpo docente"; "dificuldades/facilidades de socialização"; "relações de poder" e o "sentimento de culpa", como subcategorias para explicar esse processo de análise.

Identificamos, a partir das falas de três professores, as "facilidades/dificuldades em ingressar/integrar no corpo docente" ao observamos que os professores iniciantes, na maioria das vezes, são professores ACTs ${ }^{1}$, e que essa condição coloca o professor em situação de instabilidade, pois todos os anos ele precisa participar de processo seletivo para o ingresso no magistério. Esta incerteza é acompanhada pela dúvida de saber em qual escola irá atuar e o tempo que irá permanecer nela.

Esta particularidade no processo de contratação de professores é um fato que interfere no contato com a organização escolar e integra-se ao corpo docente. No campo da organização pedagógica, os professores iniciantes em contrato temporário passam a implementar propostas sugeridas pelos professores nativos da escola. Este parece ser o primeiro momento em que a socialização se desvela, pois a programação das propostas educacionais nem sempre corresponde às expectativas e anseios dos docentes.

Ferreira (2005) fala do poder educativo das instituições, destacando que as aprendizagens dos professores podem também ser adquiridas pela "interação" que vivenciam no contexto escolar. Garcia (2010) observa que o processo de inserção profissional é um período de tensões e aprendizagens intensivas em contextos geralmente desconhecidos, e durante o qual, os professores iniciantes devem adquirir conhecimento profissional, além de conseguirem manter certo equilíbrio emocional. É tempo em que estão conhecendo o ambiente de trabalho, se adaptando à organização escolar, além disso, precisam conciliar a vida pessoal com a profissional.

Aos professores iniciantes são dispostas as mesmas responsabilidades de um professor experiente, pois cabe a eles investigar as distintas realidades dos alunos, planejar e ministrar as aulas, adaptá-las aos que possuem mais dificuldades, criar um ambiente de aprendizagem e continuar a desenvolver a sua identidade profissional (GARCIA, 1999a). Sobre a condição de ingresso/integração com a organização escolar, os professores iniciantes entrevistados relataram que:

Admissão por Caráter Temporário.

Pensar a Prática, Goiânia, v. 17, n. 2, p. 472-484, jan./mar. 2014 476 
Normalmente os professores iniciantes são os ACTs, que na nossa cultura são os últimos nos critérios de preferência, então eles, os iniciantes, por serem ACT, encontram um panorama que já está pré-definido, eles vão para aceitar aquilo que sobrou. (Professor João).

É uma realidade diferente, tu chega querendo passar tudo o que tu aprendeu, aí nocomeço tu te desespera porque não consegue nada, então acha que está tudo errado[...]. (Professora Carmem).

Há falta de apoio nos momentos que mais precisamos, que seria justamente quando estamos iniciando. (Professora Luiza).

Os professores relatam sobre a falta de acolhimento e até uma falta de preocupação por parte da estrutura educacional em contribuir para o momento de início da carreira e ingresso na comunidade escolar, o que pode traduzir-se em um posterior abandono ou desmotivação dos professores.

Neste sentido, Medeiros; Conceição; Borowski (2012) observam que a socialização e o acolhimento são peças fundamentais para que o professor iniciante se sinta motivado na sua docência, ou até mesmo, para que não entre em processo de desinvestimento pedagógico. Este debate expressa a dificuldade de socialização dos professores contratados em regime ACT, por não terem tempo hábil para compreenderem melhor a realidade da comunidade escolar, onde estão inseridos.

Ao ingressar no ambiente escolar a tua insegurança é grande, principalmente se tu não conhece a escola [...]. (Professor João).

Eles me acolheram muito bem, muito bem mesmo, sempre comigo, eles me encaminhavam as turmas, falavam: estão em tal lugar, tu podes usar tais espaços, podes usar esses materiais, se precisar tu podes chamar. Muito bom! Senti-me bem acolhida, bem em casa, e como eu estava iniciando, foi bem importante pra mim. (ProfessoraAna).

Este acolhimento vindo dos demais professores fica evidenciado na fala do professor João, ao comentar sobre a insegurança dos iniciantes ao experimentar algo novo, em se sentir "integrado" na organização. A professora Ana acentua essa importância e até compara com o seu lar, ou seja, ape-

Pensar a Prática, Goiânia, v. 17, n. 2, p. 472-484, jan./mar. 2014 
sar de ser um ambiente desconhecido, os demais professores não deixam que isso afete o seu trabalho, dando apoio e subsídio a ela.

Outra subcategoria elaborada a partir das falas dos colaboradores foi a "facilidades/dificuldades na socialização docente". Três professores entrevistados responderam que possuem essa dificuldade. É uma espécie de parceria entre os próprios docentes para que possam trabalhar juntos em um só objetivo, em prol dos alunos. Trabalhando dessa forma, os professores conseguem compartilhar e trocar experiências e conhecimentos.

A partir dessa categoria percebemos que a socialização com o corpo docente apresenta duas faces. Uma delas nos mostra a influência positiva desse professor mais experiente com um iniciante, seja nas conversas sobre os alunos, ou até mesmo na elaboração de planos interdisciplinares. Mostra a indiferença dos professores e da estrutura escolar como um todo, que não "prepara o ambiente" para a chegada de um novo professor.

Medeiros; Conceição; Borowski (2012) apontam, sobre a influência positiva, que o professor mais experiente pode contribuir com o iniciante na reflexão sobre a sua prática pedagógica. Garcia (2010) observa que não é necessário insistir na necessidade de experiência, mas sim na qualidade dessas vivências, ou seja, na reflexão sobre elas buscando aprendizados mais avançados. Para que essas experiências se tornem significativas, é necessário haver conversões, compreensão para se tornar conhecimento.

O professor João chama a atenção para que a atuação docente esteja dentro de um projeto maior, destacando as ações de maneira integrada, compreendendo a educação enquanto formação integral do ser humano e, ainda, possibilitando a aproximação entre os professores da escola, levando a uma maior reflexão e debate dentro do ambiente escolar.

\begin{abstract}
Acredito que a educação deve ser de maneira "integrada". Porque essa questão de trabalhar cada disciplina no seu momento, seu espaço e sua vez é uma visão antiquada. Não é assim que funciona, e o trabalho com os professores (as) de outras disciplinas é muito importante para que haja um reconhecimento para as capacidades e dificuldades dos alunos. Na medida em que vamos nos inteirando mais da situação de cada aluno, vamos aprendendo mais sobre cada um deles. Assim, além de ter essa grande troca de experiências se consegue trabalhar de forma em que tenha mais significados para os alunos (Professor João).
\end{abstract}

Há, ainda, outra face dessa socialização: a influência negativa dos experientes na prática educativa dos professores iniciantes. Andrade (2006) diz que há uma resistência grande no ambiente escolar por parte dos "tradi-

Pensar a Prática, Goiânia, v. 17, n. 2, p. 472-484, jan./mar. 2014 478 
cionalistas", que talvez por comodismo ou impossibilidade diante do compromisso como educadores, impedem os iniciantes de inovarem a estrutura que já está contaminada.

Às vezes, tu chega à escola com vontade de fazer várias atividades, coisas novas, e o professor de sala às vezes não aceita, diz que vai dar muito trabalho. (Professora Luiza)

A professora efetiva de Educação Física tinha uma ideia da disciplina muito diferenciada da minha, tanto de aulas, de conteúdos e do próprio objetivo da disciplina. A sua forma de trabalhar era bem tradicional, e eu não acreditava, então eu entrei em atrito com ela. Ela não era uma pessoa que buscava compreender aquilo que a gente estava discutindo e não refletia sobre o que a gente trazia. Comecei de uma forma bem aberta buscando a professora e quando esse confronto de ideias começou a aparecer constantemente procurei me afastar. (Professor João)

O professor iniciante sempre encontrará algumas "dificuldades" no processo de socialização docente, pois as diferenças conceituais e epistemológicas constituem o fazer docente no emaranhado cultural da escola. Os mundos vividos e experienciados na mesma realidade escolar geram conflitos alimentados por relações de poder que resultam no afastamento dos sujeitos de um propósito singular, comum. Essa "dificuldade" encontrada no contexto escolar pode ser ocasionada pela "relação de poder":

Tive bastante dificuldade, ela (professora experiente) dificultou o meu trabalho ao extremo, tanto na parte de materiais, como espaço. Na verdade eu entendi que ela queria a minha vaga no próximo ano, e de alguma forma ela entendeu que deveria me derrubar, começou a falar mal de mim para outros professores. E ela não fez só comigo, fez com vários outros professores que estavam ali. (Professor Francisco)

A questão da "relação de poder" fica evidente na fala do professor Francisco, pois o mais experiente dentro do ambiente escolar se sente dono dos materiais, dos espaços, e isso pode prejudicar o professor em início de carreira. Ainda é possível analisar no relato da professora Sandra que alguns professores não estão abertos a qualquer tipo de conversa. Mesmo que esse professor experiente acompanhe o processo de transformação do conheci- 
mento, ele pode acreditar que a melhor forma de ensinar é a dele, a que ele aprendeu há tempos atrás, negando discutir ou analisar outras propostas, mantendo-se distante do professor iniciante.

A partir desses eventuais problemas com a socialização docente, alguns professores iniciantes descrevem um "sentimento de culpa", ou seja, buscam se culpar pelo seu trabalho, sempre atribuindo a si próprios as dificuldades encontradas. Sejam elas em "uma aula que não deu certo" ou dificuldades com domínio de turma, como planejamentos, entre outros fatores (FREITAS, 2002).

Freitas (2002) ainda aponta que esse "sentimento de culpa" é um fator que também pode ser analisado como uma contribuição para a sua socialização docente, pois, ao invés de se aquietar e se desmotivar, o professor busca superar essas dificuldades encontradas desenvolvendo estratégias. Essas dificuldades acabam, assim, servindo de desafios para eles se apoiarem e superarem seus medos e angústias.

Se o professor não entende que hoje muitos alunos vão ser indisciplinados, que existem várias realidades na escola, se ele não estiver preparado para isso, ele realmente tem uma desmotivação. Pode acontecer também quando o professor acha que é o melhor do mundo e que nas suas aulas vai dar tudo certo, e isso não acontece. No meu caso eu tive dificuldade com a disciplina dos alunos, mas isso serviu pra buscar mais informações com outros professores e mais recursos para que eu pudesse melhorar minhas aulas, e não me deixar desistir. (Professor João)

A fala acima nos remete a perceber como a autoestima do professor é importante nessas horas, pois se o mesmo se deixar abalar com algumas situações do cotidiano, surgem grandes riscos de ele se afastar do ambiente escolar por frustrações. Ao falar em socialização não podemos deixar de lembrar da equipe diretiva, pois, como ela faz farte do contexto escolar, exerce uma função muito importante dentro da escola e é também de extrema importância para o acolhimento dos professores, principalmente em início de carreira. Será com esse acolhimento que o professor se sentirá mais motivado e seguro para exercer sua função.

\section{Considerações Transitórias}

No processo de construção das considerações transitórias deste estudo, resgatamos o objetivo principal tratado na investigação: analisar a influência da socialização docente diante das condições dos professores em início de carreira. Neste sentido, compreendemos que os professores iniciantes

Pensar a Prática, Goiânia, v. 17, n. 2, p. 472-484, jan./mar. 2014 480 
passam por um processo de socialização no decorrer da sua vida profissional e, nesse período de inserção na carreira docente, sofrem influências positivas e também negativas dentro do contexto escolar. A dificuldade com a indisciplina dos alunos, a falta de apoio diretivo, o distanciamento dos professores de Educação Física e de outras disciplinas, além da resistência de mudança dos colegas de trabalho se configuraram como as influências negativas.

Estes aspectos nada mais são do que a falta de acolhimento planejado para receber os professores dentro da organização, tanto por parte do corpo docente quanto direção e alunos. Os professores iniciantes são na maioria das vezes ACTs, e por esse motivo quando entram na escola não possuem um contato suficiente para que a sua prática docente possa ser bem sucedida. O professor iniciante precisa estar bem seguro no ambiente escolar, ou então isso pode acabar ocasionando uma desmotivação pessoal, e essa desmotivação não deixa com que o docente prossiga o seu trabalho com clareza.

Quanto às influências positivas, a socialização assume papel central. Ao se sentirem acolhidos e seguros pela organização escolar, os professores apostam na contribuição deste movimento no processo de desenvolvimento docente. $\mathrm{O}$ diálogo é essencial para esses iniciantes que, quando se deparam com um problema, sabem a quem recorrer e a quem solicitar ajuda.

Há uma desvalorização da própria disciplina da Educação Física pelos demais professores do corpo docente. Eles pensam que esta disciplina não faz parte do contexto, sendo apenas um momento de descontração para os alunos e para que os professores de sala possam ganhar uma folga. Propomos uma pesquisa junto aos professores de outras disciplinas, sobre a importância da Educação Física dentro da organização escolar, com o intuito de compreender o porquê dessa desvalorização profissional e também pessoal.

A formação inicial é o grande alicerce do professor iniciante, pois é nela que ele se apoia para iniciar a sua docência. Mas é importante lembrar que o professor não sai da formação inicial pronto para desempenhar o seu papel de docente pelo resto de sua vida, ou seja, o professor iniciante deverá sempre ir em busca do conhecimento e procurar formas para que sua formação seja contínua. A sociedade muda, bem como os indivíduos que a constituem, sendo assim, o professor é um ser inconcluso, pois sempre deverá buscar soluções e conhecimentos para que possa qualificar sua prática educativa.

Pensar a Prática, Goiânia, v. 17, n. 2, p. 472-484, jan./mar. 2014 481 


\title{
SOCIALIZATION ON THE INFLUENCE OF THE JOURNEY TEACHING TEACHERS OF PHYSICAL EDUCATION IN EARLY CAREER
}

\begin{abstract}
To understand the influence of the teaching staff socialization in the process of becoming a Physical Education teacher at the teachers initiation's stage was the aim of this study. We have investigated the trajectory and the education practice of five Physical Education teachers in the teachers initiation's stage. We have realized that the teachers fully depend on the process of socialization, ascribing to that process a central role in the phase of ingress in the teacher career, in which the beginning teachers face a lot of doubts and distress, inherent in the process of insertion in the school enviroment. Therefore, the understanding of those feelings connected to that initial phase, starting from the approach and with a receptive welcoming of the institution itself and its teaching staff, may soften eventual disappointments with the teaching practice.
\end{abstract}

Keywords: Beginning of Teaching Practice. Initial Formation. Teaching Staff Socialization.

\section{SOCIALIZACIÓN SOBRE LA INFLUENCIA DE LA JORNADA ENSEÑANZA DE ENSENÃNTES NOVELES DEL EDUCACIÓN FÍSICA}

\section{Resumen}

Comprender la influencia de la socialización docente en el proceso de convertirse en un maestro de educación física en la fase de iniciación de la enseñanza, fue el objetivo de este estudio. Se investiga la trayectoria y la práctica de cinco profesores de educación física de educación en la etapa inicial de la enseñanza. Entendemos que dependen enteramente de los procesos de socialización, atribuyendo este proceso, el papel clave de la fase de entrada en la enseñanza, en la que los profesores son principiantes muchas dudas y ansiedades inherentes al proceso de integración en el entorno escolar. Por lo tanto, la comprensión de estos sentimientos conectados a esta etapa puede ser aliviado con este proceso y la recepción de la institución y de sus profesores.

Palabras-claves: Inicio de la Enseñanza. La Formación Inicial. Socialización del Ensenãntes.

\section{Referências}

ALVES-MAZZOTTI, Alda Judith; GEWANDSZNAJDER, Fernando. O método nas ciências naturais e sociais: pesquisa quantitativa e qualitativa. São Paulo: Pioneira, 1998. 
BERGER, Peter L.; LUCKMANN, Thomas. A Construção Social Da Realidade: Tratado De Sociologia Do Conhecimento. 34 ed. Petrópolis, Vozes, 2012.

ANDRADE, Rafael Ortega de. O PROFESSOR INICIANTE EM GEOGRAFIA: Relações entre a formação inicial e o exercício profissional. (Dissertação de Mestrado) Universidade Metodista de Piracicaba, Piracicaba, São Paulo, 2006.

FERREIRA, Lílian Aparecida. O professor de educação física no primeiro ano da carreira: analise da aprendizagem profissional a partir da promoção de um programa de iniciação a docência. (Tese de Doutorado), Universidade de São Carlos, São Paulo, 2005.

FREITAS, M. N, de C. organização escolar e socialização profissional de professores iniciantes. Cadernos de Pesquisa, n. 115, p. 155- 172, São Paulo, 2002.

GARCIA, C. M. Formação de Professores: Para uma Mudança Educativa. Estudo sobre estratégias de inserção profissional na Europa. Revista Iberoamericana de Educación, 19, p. 101-144, 1999a.

IANNONE, L. R. A organização escolar em novas versões. Revista e-Curriculum. V. 1, numero 002, 2006.

HALL, R. H. Organizações. Rio de Janeiro: Prentice/Hall do Brasil, 1982.

HUBERMAN, Michael. Ciclo de vida profissional dos professores. In: NÓVOA, A (org.) Proto/Portugal: Porto Editora, 1995.

LAKATOS, Eva Maria; MARCONI, Marina de Andrade. Fundamentos de metodologia científica. 4 ed. rev. e ampl. São Paulo: Atlas, 288 p. I 85-224, 2001.

MEDEIROS, C. da R.; CONCEIÇÃO, V. J. S. da; BOROWSKI, E. B. v. Trajetória docente de professores de educação física na fase de entrada na carreira: um estudo sobre saberes mobilizados para a construção da identidade docente. Revista: CBCE. VI sul brasileiro de ciência do esporte (2012): n.pag.web. 20/Nov. 2012. 
MIZUKAMI, M. G. N. Docência, Trajetórias Pessoais E Desenvolvimento Profissional. In: REALI, Aline Maria de Medeiros Rodrigues. MIZUKAMI, M. G. N. Formação De Professores. São Carlos: EDUFSCAR, 1996.

MOLINA NETO, V. Etnografia: uma opção metodológica para alguns problemas e investigação no âmbito da Educação Física. In: MOLINA NETO, V.; TRIVIÑOS, A. N. S.. A pesquisa qualitativa em Educação Física: alternativas metodológicas. $3^{\circ}$ ed. Porto Alegre: Ed. Sulina, p 113 - 146, 2010.

Perin, Andréa Pavan. Dificuldades vivenciadas por professores de matemática em início de carreira. (Dissertação de Mestrado), Universidade Metodista em Piracicaba, 2009.

Recebido em: 10/07/2013

Revisado em: /09/08/2013

Aprovado em: 26/09/2013

Endereço para correspondência:

victorjulierme@yahoo.com.br

Victor Julierme Santos da Conceição

Associação Prudentina de Educação e Cultura.

Av. Universitária, 1105 - Bairro Universitário

C.P. 3167 | CEP: 88806-000 Criciúma / Santa Catarina

Pensar a Prática, Goiânia, v. 17, n. 2, p. 472-484, jan./mar. 2014 